\title{
SOBRE MARTELADAS E PEDRADAS E A ESTRUTURA DE FORMAS EM -ADA DERIVADAS DE NOMES
}

Alessandro Boechat de Medeiros*

(iD) http://orcid.org/0000-0001-9925-2643

Como citar este artigo: MEDEIROS, A. B. de. Sobre marteladas e pedradas e a estrutura de formas em -ada derivadas de nomes. Todas as Letras - Revista de Lingua e Literatura, São Paulo, v. 22, n. 1, p. 1-18, jan./abr. 2020. DOI 10.5935/1980-6914/ eLETDO2012838

Submissão: setembro de 2019. Aceite: fevereiro de 2020.

Resumo: Neste trabalho, utilizando o arcabouço teórico da Morfologia Distribuída (HALLE; MARANTZ, 1993; MARANTZ, 1997), trato de formas como pedrada e cabeçada, propondo que elas sejam analisadas como um tipo de composto N-N.

Palavras-chave: Nominalizações. Compostos. Referencialidade. Flexão nominal. Morfologia Distribuida. 


\section{INTRODUÇÃo}

N este trabalho, tratarei de formas nominais como as que estão marcadas em negrito nos exemplos (1) abaixo. Como alguns artigos sobre o tema já o mostraram (SCHER, 2006; MEDEIROS, 2008; entre outros), essas nominalizações são derivadas de nomes - não de raízes acategoriais (cf. KIPARSKY, 1982; MARANTZ, 1997) -, e tais nomes denotam instrumentos usados em um tipo de evento bastante específico: pancada ou golpe dado ou sofrido por alguém ou alguma coisa. Parece claro que o signficado da nominalização não é definido pelo nome de base, em alguma negociação arbitrária do sufixo com este nome - mas independe dele, e, mesmo quando usamos um nome que não pode ser usado como um instrumento para eventos do tipo denotado pela nominalização, como macarrão (macarrãozada), interpretamos a nominalização resultante de modo regular, ainda que seu significado contrarie de algum modo nosso conhecimento de mundo.

(1) a. Mário deu uma pedrada no ladrão.

b. Maria levou uma guarda-chuvada da avó.

c. Aquela pernada me machucou à beça.

d. Uma chifrada quase matou o toureiro ontem.

e. ?O assistente de cozinha tomou uma macarrãozada na cabeça.

Mais adiante, proporei que essas nominalizações são, na verdade, compostos endocêntricos do tipo $\mathrm{N}-\mathrm{N}$, com o primeiro nome (usando aqui uma nomenclatura da gramática tradicional - ver, por exemplo, BECHARA, 2003) funcionando como determinante e o segundo funcionando como determinado. Ou seja, teríamos algo como chifre ${ }_{\mathrm{N}}-a d a_{\mathrm{N}}$ ou macarrão $_{\mathrm{N}}-a d a_{\mathrm{N}}$, dois nomes combinados para denotar um evento específico envolvendo um instrumento específico. Há, portanto, duas raizes aqui: a raiz do nome que denota um instrumento e aparentemente é a base da nominalização (por exemplo, chifre), e a raiz do segundo nome, Vad(contra IPPOLITO, 1999, para o italiano, e SCHER, 2006; MEDEIROS, 2009; entre outros, para o português), que denota "golpe" ou "pancada" envolvendo tal instrumento. Adotando o arcabouço teórico da Morfologia Distribuída (HALLE; MARANTZ, 1993; MARANTZ, 1997, 2013), desenvolverei uma análise com a qual tentarei explicar as propriedades discutidas na próxima seção.

O artigo tem o seguinte desenho: a primeira seção e suas subseções apresentam uma série de propriedades das nominalizações em -ada, estudadas neste artigo, e mostram que elas compartilham propriedades com certos tipos de compostos. A segunda seção e suas subseções propõem uma análise formal dessas nominalizações, procurando explicar ponto a ponto as propriedades discutidas na seção anterior. A terceira seção faz um resumo da discussão e aponta questões para investigação futura.

\section{Alguns fatos SOBRE PEDRADAS E MARTELADAS}

Usando alguns testes propostos na literatura (cf. KIPARSKY, 1982; ARAD, 2003), Scher (2006) mostra que nominalizações como pedrada e cadeirada envolvem, na base, os nomes pedra e cadeira, não somente suas raízes (exemplos (2)). A lógica desses testes, expressa em Kiparsky (1982), é a seguinte: palavras podem ser derivadas de raízes acategoriais ou de raízes categorizadas. Quando, 
por exemplo, temos um verbo aparentemente derivado de nome, podemos descobrir se a derivação do verbo toma a raiz acategorial associada ao nome (e não o próprio nome) nos perguntando se o significado do verbo implica o do nome. O teste abaixo serve a esse propósito:

(2) a. Paulo martelou o prego com uma pedra.

b. *Paulo acorrentou a bicicleta com uma corda.

O exemplo (2a) mostra que o verbo martelar denota uma atividade especifica, tipicamente associada ao uso de martelos, mas que não precisa envolver como instrumento um martelo. Aqui, a raiz do verbo (que também é a do nome martelo) somente define um modo específico de agir, mas não serve para introduzir o instrumento associado a esse modo. O exemplo (2b), por sua vez, nos mostra que a atividade de acorrentar envolve necessariamente o instrumento corrente.

Para Kiparsky (1982) e Arad (2003), os exemplos anteriores servem como evidência de que: 1 . o verbo martelar não é derivado do nome martelo, mas da raiz (acategorial) desse nome; 2. o verbo acorrentar é derivado do nome corrente, pois seu significado implica o significado do nome. Os autores apresentam outras evidências para essas afirmações, evidências morfofonológicas e fonológicas, mas não vou discuti-las aqui.

Scher (2006) retoma esse argumento para mostrar que as nominalizações sob investigação neste texto envolvem nomes na sua base, não raízes. Os exemplos a seguir ilustram seu ponto:

(3) a. Pedro deu uma pedrada no ladrão com uma pedra pome/*um coco verde.

b. João levou uma correntada nas pernas com uma corrente de bicicleta/ *uma corda grossa.

c. João deu uma martelada no ladrão com o martelo do pedreiro/*com uma das pedras do entulho.

O argumento usado para os exemplos em (3) é o mesmo usado para os exemplos em (2): as nominalizações em negrito têm como base um nome, não uma raiz acategorial, pois seus significados incluem o significado do nome de base.

Medeiros (2009) apresentou outro argumento para mostrar que essas formas são derivadas de nomes: algumas bases apresentam terminações que só encontramos em finais de palavras (que necessariamente envolvem raízes categorizadas), como mostram os exemplos a seguir:

(4) a. Pedro levou uma limãozada na cabeça.

b. João deu uma bastãozada ${ }^{1}$ involuntária no cachorro.

c. O punguista levou uma mãozada da vítima.

Nos itens de (4), a terminação -ão, gerada por regras fonológicas deflagradas no contexto de fronteira final de palavra em português, se realiza no interior da nominalização. Isso nos mostra que a derivação não pode partir da raiz, mas do nome - e, ademais, deve incluir algo que defina uma fronteira de palavra interna à nominalização, de modo que as regras que geram a terminação -ão no interior da forma limãozada se apliquem. Note-se que o mesmo não ocorre em palavras como limonada ou limoeiro (cf. MEDEIROS, 2009).

1 Há variante dicionarizada para essa forma, bastonada, que significa pancada ou castigo aplicado com bastão. 
Essa discussão sugere que a base da nominalização em -ada não é somente um radical nominal, mas inclui fronteira de palavra. Além disso, como veremos adiante, em alguns casos fica explícito que o nome do instrumento, o suposto nome de base, está no plural, como em limõezadas. Sendo assim, parece razoável perguntar se tais formas não poderiam ser algum tipo de composto, em que um nome se combinaria a um suposto nome ada que denota algo como pancada, golpe. Ou seja, teríamos aqui um composto do tipo N-N, com a base e a terminação ada sendo dois nomes distintos.

Algumas análises para o diminutivo no português (e para os advérbios em mente) apresentam argumentos para defender que diminutivos envolvem composição, em que o nome de base se combina com outro nome, algo como inho ou zinho (por exemplo, BACHRACH; WAGNER, 2007, entre outros). A pergunta que nos fazemos aqui é se argumentos semelhantes podem ser usados como evidência de que os nominais em -ada aqui estudados são compostos.

Compostos N-N em português são, pelo menos, de dois tipos, segundo as gramáticas normativas: aqueles em que o determinado precede o determinante, como tubarão-baleia ou palavra-chave, e aqueles em que o determinante precede o determinado, como cineclube ou espaçonave. No caso das nominalizações em -ada, se elas forem compostos N-N, o serão do segundo tipo, com o determinante precedendo o determinado, pois o núcleo do composto seria necessariamente a terminação ada, com o nome de base funcionando como seu elemento determinante ou especificador. Uma coisa interessante sobre os compostos N-N do tipo determinante-determinado em português é que plurais e diminutivos ficam no final do composto, ao contrário dos compostos do tipo determinado-determinante (cf. LEE, 1997; NÓBREGA, 2015, entre outros). Vejam-se os exemplos a seguir:

(5) a. Cheque-caução/cheques-caução/chequinho-caução

b. Tubarão-baleia/tubarões-baleia/tubarãozinho-baleia

c. autopeça/autopeças/autopecinha

d. tomaticultura/tomaticulturas/tomaticulturinha

Ademais, enquanto nos compostos N-N do tipo determinado-determinante verifica-se alto grau de preservação das vogais e seus acentos nas palavras que compõem o composto, como vemos em (6a), nos compostos do tipo determinante-determinado, o comportamento das vogais é menos previsivel: o exemplo (6b) mantém obrigatoriamente a altura da vogal tônica do primeiro nome (o determinante), mas essa altura não ocorre em (6c) e (6d), em que a vogal sobe obrigatoriamente ou opcionalmente.

(6) a. chéque-caução (*chêque-caução)

b. xerécopênis (*xerêcopênis)

c. ferrovia (fêrrovia/??férrovia)

d. merdolândia (mêrdolândia/mérdolândia)

Ao contrário do que se espera de uma composição N-N do tipo determinante-determinado, as formas nominais em -ada aceitam alguns plurais (irregulares) no elemento determinante, como vemos em (7a) a seguir, ainda que, como nos compostos de que estamos falando, não aceitem diminutivos ou aumentativos neste (suposto) elemento (cf. (7d)). Com relação às propriedades das vogais tônicas dos nomes de base, as nominalizações em -ada têm o comportamento pouco 
previsivel dos compostos determinante-determinado: quando a vogal temática do nome de base dá lugar à primeira vogal da terminação -ada, a altura das vogais tônicas médias baixas da raiz sobe obrigatoriamente, para alguns itens, no contexto da terminação -ada, como o mostram os exemplos (7a, b) abaixo; mas isso não é verdade sempre, como o mostram $(7 \mathrm{e}, \mathrm{f})$. Além disso, para os casos em que o nome de base não tem uma vogal temática, como nas palavras fóssil em (7g) e móvel em (7h), subir a altura da vogal tônica do nome de base na nominalização em -ada é simplesmente vedado.

(7) a. portõezadas/limõezadas

b. pédra/pêdrada/*pédrada

c. bóla/bôlada/*bólada

d. *pedrinhada/*pedrãozada/*pedrõezadas/*pedronada

e. moéda/moêdada/moédada

f. panquéca/panquêcada/panquécada ${ }^{2}$

g. fóssil/fóssilzada/*fôssilzada

h. móvel/móvelzada/*môvelzada

Esses fatos mostram que os compostos N-N do tipo determinante-determinado e as nominalizações em -ada investigadas neste trabalho compartilham muitas propriedades.

Com relação à única coisa, das discutidas anteriormente, que aparentemente distingue os compostos determinante-determinado das nominalizações em -ada, a saber, a presença de plural no primeiro elemento, gostaria de fazer as seguintes considerações. Quando a vogal temática do nome de base dá lugar à primeira vogal da terminação - ada, o plural "interno", que é regular, não é permitido, ou pelo menos não é manifesto na estrutura morfofonológica da palavra. Por outro lado, quando o plural é "irregular", como encontramos nas palavras com terminação -ão ou em palavras como pincel (cf. (8b)), ele é licenciado (fica visivel). Ou seja: a pluralização dos nomes de base das nominalizações aqui investigadas é bastante restrita. Os exemplos em (8) o mostram:

(8) a. pedras/*pedrasadas (ou *pedrazadas) /*pedraszadas

b. pincéis/pincelzadas/pincéizadas ${ }^{3}$

Curiosamente, algo semelhante ocorre em certos compostos $\mathrm{N}-\mathrm{N}$ do inglês, em que somente plurais irregulares se manifestam nos nomes que são, na terminologia aqui usada, determinantes - nunca os plurais regulares. Vejam-se os exemplos a seguir:

(9) a. mice trap (armadilha para camundongos)

b. *rats trap (armadilha para ratos)

A comparação com os compostos N-N do inglês, em que o primeiro nome é sempre o determinante e o segundo nome, o determinado, nos fornece mais elementos que sugerem um paralelismo entre as nominalizações aqui investigadas e a estrutura de compostos.

2 Agradeço a Gean Damulakis por esse exemplo. Um teste com logatomas pode vir a ser uma etapa futura deste trabalho, para verificar se a altura da vogal tende a se preservar ou não no contexto de -ada.

3 Pincelzada e pincelada são coisas distintas: a primeira denota golpe com pincel; a segunda, uma atividade mais específica com o pincel, particularmente em pintura artística, ou mesmo algo que caracteriza o estilo de um pintor, também no âmbito artístico. 
Para fechar esta seção, gostaria de comentar o seguinte. Se as nominalizações em -ada são compostos nos quais sua terminação é o nome determinado, esperamos encontrar usos da terminação (z)ada em contextos como $X$ deu uma (boa) (z)ada em $Y$, tendo (z)ada o significado de golpe ou pancada sem a especificação de um instrumento. Minhas intuições de falante não são seguras quanto a essa possibilidade, que é exemplificada em (10) a seguir:

(10) Sabe aquele socador de pilão ali no canto? Dei uma boa?*(z)ada com aquilo na cabeça do cara que invadiu minha casa ontem. O pilantra está hospitalizado.

Não tenho muito a dizer sobre esse problema. Contudo, creio que dificuldade semelhante se coloca para as abordagens que consideram os diminutivos como compostos, pois, do mesmo modo, -inho jamais é usado isoladamente, e a assunção de que -zinho é uma palavra independente é bastante controversa.

Entretanto, assumindo certos pressupostos da Morfologia Distribuída, podemos imaginar que o significado da raiz do suposto nome ada seja definido somente no contexto específico desses compostos. Ou seja, o nome ada não poderia ocorrer isoladamente porque não haveria conteúdo enciclopédico listado para sua raiz num contexto em que não haja um nome formando um composto de determinado tipo com ele.

$\mathrm{Na}$ próxima seção, mostrarei que, interessantemente, o nome de base das formas aqui estudadas fornece referentes no discurso, que podem ser recuperados por pronomes - e mais: que o traço de número desses nomes também fica acessivel aos pronomes que os retomarão.

\section{Sobre a referencialidade e a pluralidade dos nomes de base}

Observem-se os exemplos a seguir, em (11). Neles, fica claro que os nomes de base das nominalizações em -ada, os quais denotam instrumentos, fornecem referentes para pronomes no discurso:

(11) a. Márcio levou uma prateleira da no porão de sua casa, mas por sorte ela ${ }_{i}$ não tinha muita coisa em cima e ele não se machucou.

b. ?Maria levou uma limão ${ }_{i}$ zada no meio da testa, mas por sorte ele $_{i}$ estava meio passado e mole, e não machucou para valer.

Em (11) os nomes prateleira e limão introduzem referentes no discurso, que podem ser recuperados por pronomes em outras proposições que compõem o contexto, com maior ou menor sucesso. Nos dois exemplos, o nome de base da nominalização se torna antecedente do pronome da sentença seguinte - e tópico dela.

Note-se que a correferência entre nomes de base em formas morfologicamente complexas e pronomes costuma ser pelo menos mais degradada do que quando a mesma correferência é estabelecida nos exemplos (11). Vejam-se as sentenças em (12):

(12) a. ??Joana faz críticas ferozes aos $\operatorname{marx}_{\mathrm{i}}$ istas, mas sempre $\mathbf{o}_{\mathrm{i}}$ considerou/ considerou ele $e_{i}$ um dos maiores pensadores do século XIX.

b. *Joana tentou parafus $\mathbf{s}_{\mathrm{i}}$ ar a dobradiça da porta, mas ele $\mathrm{i}_{\mathrm{i}} / \mathbf{s}$ tinha/m perdido a fenda e ela não conseguiu fazer o serviço. 
Enquanto em (11) a recuperação da referência do nome de base por um pronome em outra sentença é trivial, as coordenações em (12) não propiciam os mesmos julgamentos. O pronome ele (ou o clítico o) em (12a) não recupera trivialmente o nome do filósofo Karl Marx no interior do nome marxistas. Do mesmo modo, a correferência do pronome com o nome de base do verbo parafusar (que, segundo o critério de Kiparsky, seria denominal, não derivado de uma raiz acategorial) é proibida em (12b). Ou seja, nos exemplos em (12), os nomes de base não fornecem antecedentes diretamente recuperáveis no discurso, antecedentes que possam ser ou tornar-se tópicos de outras sentenças através de um pronome.

Fato ainda mais interessante a respeito da recuperação da referência dos nomes de base das nominalizações em -ada investigadas aqui pode ser visto nos exemplos a seguir, em que o nome de base está no plural:

(13) a. Pedro levou umas portãozadas quando tentou entrar no terreno. ?Eles estavam batendo forte por causa do vento.

b. Pedro levou umas portõezadas quando tentou entrar no terreno. Eles estavam batendo forte por causa do vento.

c. Pedro levou umas portõezadas quando tentou entrar no terreno. ??Ele estava batendo forte por causa do vento.

Meus julgamentos a respeito desses dados são os seguintes: (13b) é perfeita; (13a) é um pouco pior do que (13b), mas mais aceitável do que (13c). A comparação entre os exemplos nos mostra que a referência plural é recuperada por um pronome plural no discurso, e que a não "concordância de número" entre o pronome e o nome de base degrada combinações de sentenças como as apresentadas em (13). Particularmente interessante é o fato de que o plural do nome de base tem mais força para impor uma concordância com um pronome que venha a recuperar sua referência do que o singular, como mostra a comparação entre (13a) e (13c) $)^{4}$.

A combinação, contudo, de um nome de instrumento no plural e um ada singular é vedada, como mostra (14) a seguir.

(14) *Pedro levou uma portõezada quando tentou entrar no terreno.

Isso tem uma explicação simples: havendo mais de um instrumento, haverá necessariamente mais de um golpe ou pancada. Ou seja, cada instrumento particular, cada entidade que é um instrumento, especificará um conjunto de eventos. A recíproca, contudo, não é verdadeira: os eventos não definem os instrumentos, e um só instrumento pode estar associado a mais de um evento, assim como vários eventos podem envolver vários instrumentos diferentes do mesmo tipo. Isso não só licencia a forma portãozadas, em que o nome portão está no singular, mas a nominalização está no plural, como também explica a aceitabilidade (parcial) de (13a).

$\mathrm{Na}$ próxima seção, em que desenvolverei minha análise, proporei que um núcleo de número, $\#^{5}$, toma o nome de base (ou o primeiro nome do composto

4 Em consultas informais, observei que nem todos a quem consultei concordavam com meus julgamentos a respeito desses dados Alguns não consideravam que o plural interno fosse referencial, e me pareceu que encaravam o plural interno como uma espécie de concordância opcional entre o nome interno e o plural da forma nominal derivada. Alguns (poucos, entre os consultados) não aceitavam nenhum tipo de plural interno. Essas diferenças são interessantes e merecem investigação futura.

5 O núcleo \# pode incluir não só o traço de número, mas outros traços, como traços que definam referencialidade. Assumirei isso neste trabalho. 
com ada) nas nominalizações e, com isso, não só licencia a pluralização interna à nominalização como também permite a recuperação anafórica deste nome por pronomes, no plural ou no singular. Isso não acontece com marxistas ou parafusar, em que a palavra derivada é construída sobre um $n$, e isso dificulta ou simplesmente impede a recuperação anafórica, mesmo com a ajuda de um contexto.

\section{A ANÁLISE}

Nóbrega (2015) divide os compostos N-N em português em três tipos, segundo critérios morfológicos: aqueles que envolvem dois radicais, com somente um acento (morfólogo); os que envolvem um radical e uma palavra, com dois acentos (cervejochato); e aqueles que envolvem duas palavras, também com dois acentos (peixe-espada). Os radicais presentes nos compostos dos dois primeiros tipos não apresentam qualquer propriedade flexional - são radicais, não palavras. Nos compostos do tipo radical-palavra, é comum que tenhamos uma vogal de ligação (cervej-o-chato), a não ser que a palavra com a qual o radical forma o composto comece com uma vogal (psic-análise).

$\mathrm{O}$ que chamamos na seção anterior de compostos N-N do tipo determinante-determinado seriam tipicamente os compostos $\mathrm{N}-\mathrm{N}$ do tipo radical-palavra na classificação morfológica de Nóbrega (2015). Isso nos levaria à conclusão de que, sendo acertada a hipótese de que as nominalizações em -ada aqui estudadas são compostos, tais formas nominais seriam compostos do tipo radical-palavra. $\mathrm{E}$, com efeito, algumas propriedades dessas nominalizações apontam neste sentido. Em primeiro lugar, temos dois acentos: em lapiszada (golpe com lápis), por exemplo, temos claramente dois acentos: làpisáda; além disso, a nasalidade das vogais das sílabas tônicas de alguns nomes se preserva quando tais nomes servem de base para a nominalização, mesmo quando essas sílabas deixam de carregar o acento principal: por exemplo, num improvável golpe cujo instrumento é uma cama ('kãma), a forma derivada é cãmáda, não camada (que quer dizer outra coisa). A segunda é que, ao contrário dos compostos N-N do tipo palavra-palavra, em que o plural ocorre (quase sempre exclusivamente) no primeiro membro, os plurais das nominalizações em -ada sempre são marcados no segundo membro do suposto composto (pedradas), sendo impossivel sua marcação somente no primeiro membro (*pedras-ada). Do mesmo modo, diminutivos só são possiveis no suposto segundo membro, nunca no primeiro (pedradinha, *pedrinhada). Por fim, a vogal temática final do primeiro membro sempre cai, sendo substituída pela vogal inicial do suposto segundo nome (martelo-martelada).

Contudo, uma das dificuldades de se defender que as nominalizações aqui analisadas são compostos do tipo radical-palavra, no português, está na ocorrência, ainda que restrita, de plurais no primeiro membro. Ora, se há plural, então o primeiro membro não é mero radical, pois tem uma camada flexional.

Ademais, veja-se que os compostos do tipo radical-palavra não disponibilizam referentes no discurso com as propriedades definidas pelo primeiro membro (isso é característica dos compostos $\mathrm{N}-\mathrm{N}$ do tipo palavra-palavra), como o vemos em (15) a seguir; os nomes de base das nominalizações em -ada, contudo, os disponibilizam, como vimos em (11) e (13).

(15) a. Construí a melhor espaço ${ }_{i}$ nave que se possa imaginar, mas viajar por ? *ele $e_{i}$ é sempre muito difícil. 
b. Pratico a tomati ${ }_{\mathrm{i}}$ cultura há muitos anos e com muito empenho, mas *eles nunca foram muito saborosos.

c. Os cervej ${ }_{i}$ ochatos sempre aparecem quando ??ela ${ }_{i}$ está bem gelada.

Ao que parece, se as nominalizações em -ada são de fato compostos, elas não podem ser trivialmente classificadas como compostos do tipo radical-palavra, pelas razões apresentadas anteriormente; tampouco serão o tipo comum de composto $\mathrm{N}-\mathrm{N}$ palavra-palavra em português, em que o determinado precede o determinante, pois, além de, nas formas em ada, o primeiro membro ser o determinante, não o determinado, o suposto primeiro membro não aceita diminutivos (ou aumentativos) e nem todos os tipos de plural são licenciados. O que fazer, então?

Vou explorar as possibilidades que o quadro teórico adotado aqui oferece. Uma vez que palavras (e compostos) são gerados na sintaxe para a Morfologia Distribuida, vou supor que 1. seja possivel haver extensões funcionais de nomes (ou seja, o nó que alberga traços de número) dentro de palavras e de compostos, com certos limites; e 2 . que o que vai diferenciar palavras morfologicamente complexas de compostos será a presença de mais de uma raiz - palavras morfologicamente complexas trazem somente uma raiz e afixos; compostos trazem mais de uma raiz.

$\mathrm{Na}$ presente análise, as nominalizações em -ada serão o resultado da adjunção do nome do instrumento (com sua extensão funcional, que inclui o núcleo de número) ao nó $n$ resultante da adjunção da raiz $\sqrt{ }$ ad- ao núcleo nominalizador, conforme o esquema (16) a seguir. Essa estrutura, quero crer, será semelhante à estrutura dos compostos do tipo radical-palavra ${ }^{6}$, mas com uma diferença importante: enquanto esta envolve a adjunção de dois nomes no nível (morfos)sintático $n$, a primeira adjungirá um nó \# ao nome que encabeça o composto. Apesar de aparentemente não ocorrer nos compostos que tradicionalmente se discutem na literatura, é uma possibilidade da teoria, que talvez ocorra em outros contextos morfológicos. O esquema abaixo, para limãozada, ilustra as ideias aqui contidas.

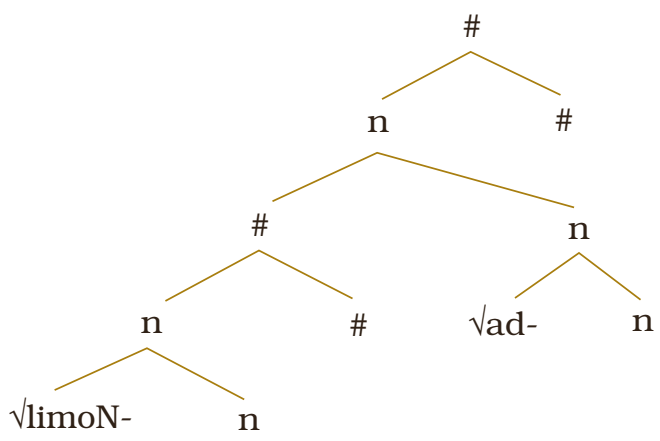

6 A proposta feita em (16) é bastante simplificada, assumindo que uma adjunção interna a um nível $n$ seria suficiente para explicar as propriedades das formas sob análise. Pode ser que haja, no composto aqui defendido, algum núcleo funcional estabelecendo as relações que encontramos tipicamente em compostos, como na proposta de Di Sciullo (2005) (ver também MINUSSI, 2011, para uma abordagem semelhante no português), mas não vou tomar partido de uma abordagem específica aqui. 
Por envolver uma estrutura funcional de número dentro do composto, este será no mínimo menos sujeito a idiossincrasias de significado, ou seja, ao contrário dos compostos radical-palavra ou radical-radical, em que podemos encontrar idiossincrasias semânticas associadas às partes (ferrovia, por exemplo, não se refere necessariamente a uma via para ferros ou mesmo feita de ferro), os significados das partes são sempre os mesmos: instrumento-golpe.

Ademais, defendo aqui que é o fato de o nome do instrumento envolver uma estrutura flexional que lhe atribui a propriedade de referencialidade - ou seja, o fato de haver um núcleo \# tomando o $n$ que domina a concatenação do nominalizador com a raiz do nome do instrumento ao qual este nome se refere faz com que o nome deixe de denotar um conjunto de propriedades ou um conjunto inespecífico de entidades do tipo definido pela raiz e passe a denotar uma ou mais entidades com as propriedades definidas pela raiz do nome. Se o traço albergado por \# for [singular] (ou [-plural]), haverá uma só entidade que poderá ser referenciada (retomada, por exemplo, por um pronome); mas se o traço for [plural] (ou [+plural]), haverá mais de uma entidade do mesmo tipo.

Podemos pensar ainda que, havendo um núcleo flexional de número, garantimos que temos fronteira final de palavra no que chamamos até aqui de nome de base da nominalização. Isso faz com que as operações fonológicas aplicáveis nessa fronteira sejam deflagradas, como a conversão de uma terminação como /oN/ das raízes de limão e bastão na terminação /ãõ/. Também faz com que, no caso de o nome do instrumento estar no plural (no caso de o núcleo \# interno albergar o traço [+plural]), aconteçam as mudanças típicas dos plurais irregulares, como a conversão do /1/ final de pincel em [j], na forma pinceizadas.

A proposta também incluirá uma raiz $\sqrt{ }$ ad-, que será a raiz do nome ada que comporá com o nome do instrumento. Como o composto denota eventos de golpear, bater, que são especificados pelos instrumentos denotados pelo primeiro nome, vou assumir que é a adjunção da estrutura funcional projetada pelo nome do instrumento ao $n$ que se forma a partir da raiz $\sqrt{\text { ad- que especifica o }}$ tipo de golpe/pancada (cf. (16)) denotado pela forma final. Um segundo núcleo \# de número se combina com o resultado da adjunção e nos informa se se trata de evento singular ou plural.

No esquema (16), há duas raízes, o que deixa claro que se aposta na ideia de composição para tratar das nominalizações em -ada investigadas aqui. O fato de haver uma raiz $\sqrt{ }$ ad- é importante para a proposta porque, como para a imensa maioria dos trabalhos em Morfologia Distribuída, somente as raizes são capazes de introduzir conteúdos enciclopédicos numa estrutura sintática; se a sequência ada fosse a realização de um afixo (como, por exemplo, em SCHER, 2006), ela não deveria contribuir com um significado como "golpe", "pancada", "batida", que é claramente enciclopédico. E não há muitas razões para se defender que de algum modo a raiz do nome do instrumento inclua também esse significado no contexto específico de um suposto afixo -ad- (ou uma combinação de afixos, como se defende em, por exemplo, IPPOLITO, 1999, para o italiano e MEDEIROS, 2008, para o português). Assim, assumir que temos, nessas formas, duas raízes, é uma saída justificável dentro dos pressupostos do referencial teórico adotado. 


\section{Sobre a morfologia dos compostos ada}

Nas seções anteriores defendi que o primeiro nome do suposto composto ada possui camada flexional sintaticamente anexada a este radical nominal, podendo portar o traço [+plural], por exemplo. Contudo, o expoente fonológico de plural, o /s / final, não pode ser inserido no nó de flexão plural do primeiro nome do composto ada. É o caso de todos os nomes com plural regular, que terminam com uma das três vogais temáticas do sistema nominal do português (pedradas $\mathrm{x}$ *pedrazadas ou *pedraszadas). O que está acontecendo aqui? A presença do traço plural no nó de flexão do nome interno seria permitida ou não por propriedades morfológicas desse nome (como o fato de esse nome ter uma vogal temática)? A teoria adotada aqui não admite essa possibilidade. Então, qual seria a saída?

Para começar a discussão, gostaria de fazer a seguinte pergunta: a consoante /z/ em formas como limõezadas é a realização do /s/ plural do nome do intrumento num contexto intervocálico ou é somente uma consoante epentética inserida entre o alomorfe plural da raiz de limão e a raiz do nome ada? Note-se que, tipicamente, a marca de plural, que é desvozeada em português, passa a vozeada quando precede uma vogal na palavra seguinte, como em casas amarelas (kázazamarćlas). Portanto, poderíamos imaginar que sim, que se trata da manifestação do /s/ plural aqui. Mas, como está dito no primeiro parágrafo desta seção, teríamos a óbvia dificuldade de explicar por que a sibilante é proibida em plurais de palavras como pedrada ("pedrazadas) ou martelada ( ${ }^{*}$ martelozadas). Ademais, a mesma sibilante parece ser a consoante epentética default que antecede a forma ada nos inúmeros casos em que o nome do instrumento não possui uma vogal temática, como movelzada, ou termina com algum tipo de ditongo, como limãozada, o que nos mostra que não necessariamente /z/ em portõezadas é a manifestação do /s / plural - e, de fato, os plurais irregulares são justamente os plurais dos nomes que não terminam com as vogais temáticas descritas na literatura, ou que terminam com ditongos. Por fim, parece-me que quando quero dizer que dei um golpe em alguém ou algo com um lápis, eu pronuncio tanto o /s / final de lápis quanto a consoante / z/ que antecede a forma final ada (lapiszada $)^{7}$. Assim, se a marca de plural estivesse sendo pronunciada em casos como o de limóezadas, eu esperaria encontrar o mesmo fenômeno, mas não é esse o caso. Vou assumir, portanto, que não, que a sibilante que antecede a forma ada em palavras como pinceizadas e portõezadas não é a marca de plural, mas uma consoante epentética que entra sempre que a raiz ou o radical do nome do instrumento não termina com uma das três vogais temáticas nominais da língua, ou termina com ditongos. Ou seja, mesmo nos plurais irregulares internos às nominalizações, a presença de / $z$ / não é o expoente fonológico do traço plural do nó de flexão interno, ainda que essa pluralidade fique visivel, em alguns casos, por conta de mudanças nas rimas das raízes. Mas o problema ainda não foi resolvido, e ainda não temos uma explicação para a não ocorrência de plurais regulares internos. Tentarei resolver esse problema com um conjunto de regras que apresentarei a seguir, começando por propor a seguinte lista dos itens que realizam o nó \# nos nomes:

7 Sequências como $[\mathrm{S} \mathrm{s}]$ ou [ $\mathrm{S} z]$ não deveriam ser toleradas em português. Somente nos casos em que uma parte da literatura chama de compostos pós-lexicais (ver, por exemplo, LEE, 1999) isso é aceito (médicos-cirurgiões; LEE, 1999, p. 5). Talvez isso seja mais uma indicação de que temos composição aqui. 

a. [\# +plural] $\leftrightarrow / \mathrm{s} /$
b. [\#] $\leftrightarrow \varnothing$

A lista (17) nos diz que sempre que o nó \# albergar o traço [+plural] o expoente /s / será inserido em \#; nos outros contextos (em que o nó \# alberga o traço [-plural] ou mesmo nenhum traço de número), teremos um expoente zero.

Vamos supor agora que o alomorfe da raiz do nome do instrumento será sensível ao valor do traço albergado pelo nó de número, e será inserido antes de quaisquer operações morfológicas que ocorram nas camadas acima do nó $n$ (que seria uma fase; cf. MARANTZ, 2013). Assim, por exemplo, para a forma pinceizadas, se o nó \# albergar o traço [+plural] em (16), a raiz da palavra pincel sofrerá um reajuste que modificará sua rima na presença do traço [+plural] em \#, gerando a forma / pinsej/. Para o caso de nomes como limão, cuja raiz é /limoN/, quando o traço albergado por \# é [+plural], a raiz passa a /limoNe/, e na PF operações fonológicas, no contexto de um nó \# (talvez em outra fase da derivação), se aplicam gerando a forma limõe.

$\mathrm{Na}$ fase seguinte, acima de $n$, proponho que se aplique a regra de empobrecimento (18) ao nó \# interno, apagando os traços de número (mas deixando outros traços que o nó venha a albergar). De fato, isso parece ser uma restrição mais geral, que se aplica a compostos em que o primeiro elemento é um modificador ou determinante do (adjunto ao) segundo (cf. (9)). A regra tem a seguinte forma ${ }^{8}$ :

(18) Se \#P for adjunto a $n$, então:

$$
[ \pm \text { plural }] \rightarrow \varnothing
$$

Note-se que, com esse apagamento, o que restará como primeiro membro do composto, no singular, nos plurais regulares e nos plurais irregulares, será uma raiz frequentemente seguida de uma vogal temática, ou uma raiz com a rima mudada.

Podemos agora imaginar que, como no caso dos compostos do tipo radical-palavra, a vogal temática do primeiro nome (ou simplesmente sua vogal final) é apagada no contexto do segundo nome quando este começa com uma vogal - e, assim, a raiz ou radical do primeiro nome, sem a vogal temática, se junta imediatamente a este segundo nome, formando o composto. No final das contas, pelo menos do ponto de vista fonológico, a forma em ada será semelhante a um composto do tipo radical-palavra, seja esse radical o de uma forma no singular ou o de uma forma no plural - a única diferença em relação aos compostos do tipo radical-palavra ocorreria nos casos em que regras fonológicas de final de palavra se aplicam sobre a forma da raiz, como vimos anteriormente para raizes como a do nome limão.

A seguir, apresento o passo a passo da derivação de duas formas ada, uma com o nome do instrumento no singular e outra com o nome do instrumento no plural (plural irregular). Comecemos com a forma martelada:

\footnotetext{
8 A regra de empobrecimento aqui apresentada é bastante heterodoxa, uma vez que, ao contrário de outros exemplos de empobrecimento na literatura, em que a presença de um traço em um determinado nó dispara a operação naquele nó, aqui a operação é disparada em um determinado contexto. Vou manter, entretanto, essa proposta, mesmo que isso não seja rigorosamente o que se toma por empobrecimento na literatura.
} 
(19)

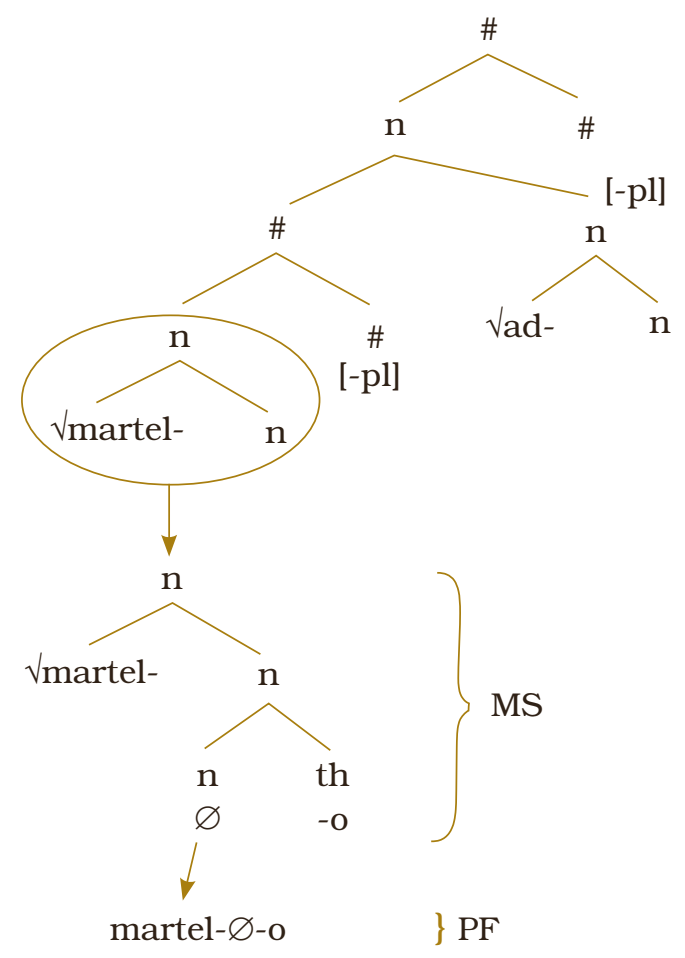

Esse esquema representa a derivação após a inserção dos alomorfes das raízes. Na fase nominal (MARANTZ, 2013; EMBICK, 2010), na MS, entram os nós temáticos (OLTRA-MASSUET, 1999). A forma final da fase $n$ será dada na linha que corresponde à $\mathrm{PF}$ no esquema.

O esquema (20) apresenta a fase seguinte, na MS, em que a regra de empobrecimento se aplica sobre o nó \#, apagando seu traço de número. A estrutura (20) a seguir, que é uma simplificação de vários passos derivacionais que não são relevantes para os nossos propósitos, representa a estrutra morfológica com a inserção dos nós temáticos e de todos os expoentes fonológicos. Conforme as regras em (17), teremos a inserção do expoente zero em \#.

(20)

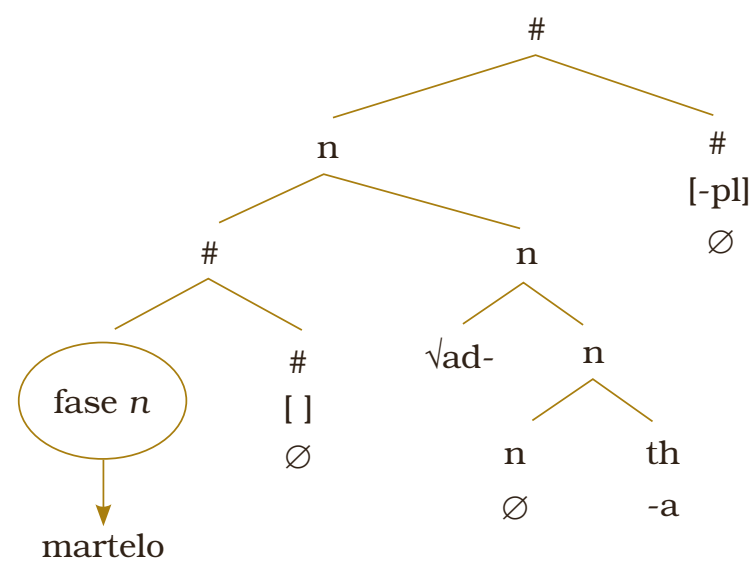


Na fonologia, a vogal temática (ou a vogal final) de martelo é apagada, conforme a representação a seguir:

(21) martelo-ad-a $\rightarrow$ martel- $\varnothing$-ada $\rightarrow$ martelada $^{9}$.

Resta explicar como a vogal tônica do nome martelo, $[\varepsilon]$, sofre a neutralização no contexto de ada. Como vimos antes, a neutralização, nas formas em ada, ocorre somente quando temos uma raiz que pede por uma vogal temática no contexto nominal. Ou, por outros termos, quando o final é ada, não zada. E, mesmo nesses casos, isso não é garantido, como me parece ser o que ocorre com panquecada (pankskada/pankekada), petecada (petckada/petekada) ou melecada (melskada/ melekada). Minha proposta tateante é que a altura da vogal tônica não fique definida na fase $n$, dependendo da fase seguinte. Se o que vier acima de $n$ for um núcleo \# tomado por um D ou adjungido a outro \# (seria o caso das ocorrências livres e diminutivos; cf. BACHRACH; WAGNER, 2007), a tônica, em nomes como martelo, panqueca, pedra etc., será média-baixa; se houver adjunção de $n$ ou \# a outro nível mínimo $x$, como outro $n$, a situação aqui investigada e talvez a dos compostos N-N do tipo radical-palavra, há variação, em que os itens novos tenderiam a permitir a preservação da altura da vogal tônica que o nome livre tem; se tivermos outros morfemas categoriais acima dessa camada (o que tradicionalmente chamamos de derivação), teremos neutralização da tônica.

Agora vejamos a derivação de uma forma em ada com o nome do instrumento no plural, sendo esse um plural irregular. O exemplo será com a forma pinceizadas:

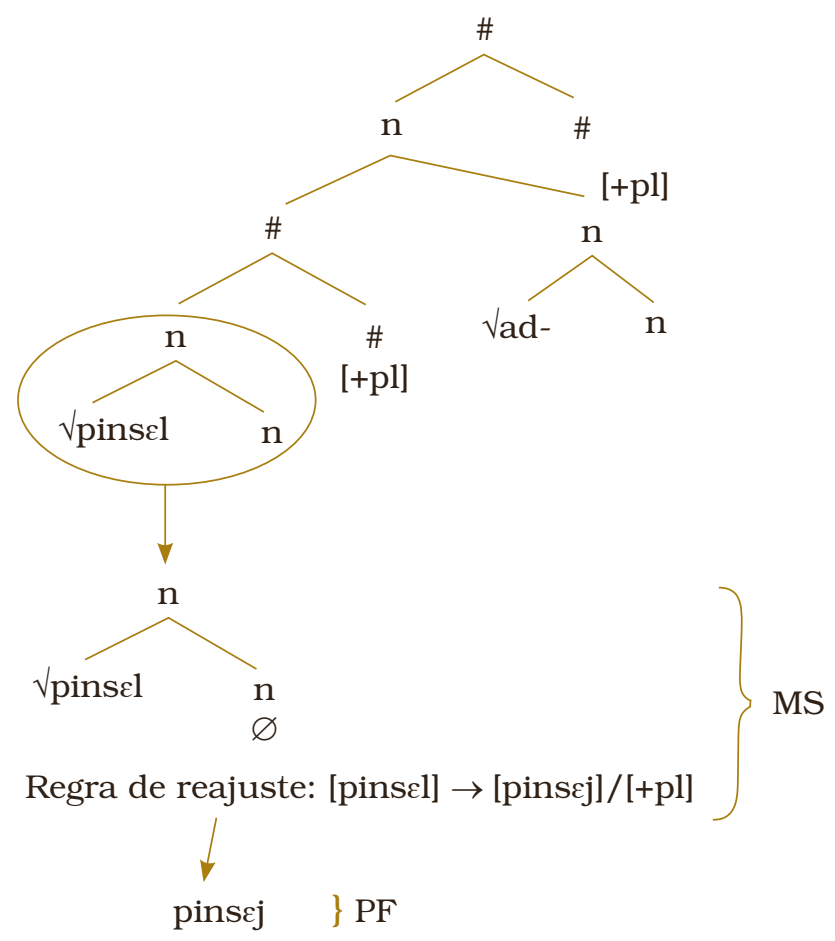

O apagamento da vogal final deve ser posterior às operações fonológicas que se aplicam sobre determinados alomorfes, como a conversão de limoNe em limõe, por exemplo. Em casos como esse, cria-se um ditongo que desfaz o contexto de aplicação da regra de apagamento da vogal final (temática) do primeiro nome. 
Após a inserção da raiz (/pinscl/), aplica-se, na MS, a regra que muda a rima da raiz, que passa a ser pinscj, por conta da presença do traço [+plural] em \# (vamos supor, seguindo vários autores, entre eles EMBICK, 2010, que a estrutura flexional pode influenciar a escolha do alomorfe da raiz na fase nominal, desde que o núcleo nominalizador seja um zero fonológico - e esse é o caso aqui). $\mathrm{Na}$ fase seguinte, aplica-se a regra de empobrecimento (18) que apaga o traço de número do nó \#. O esquema (23), uma representação simplificada das fases seguintes da derivação, representa a estrutura após as inserções dos expoentes fonológicos na estrutura morfológica (MS).

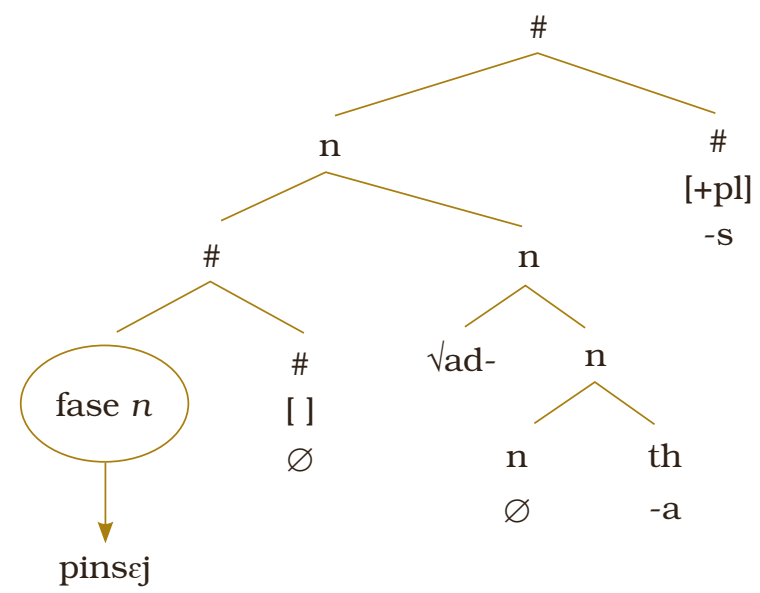

$\mathrm{Na}$ fonologia, temos a inserção de uma consoante epentética default, o [z], conforme (24) a seguir:

(24) pinscj-adas $\rightarrow$ pinsej-z-adas $\rightarrow$ pinsejzadas

\section{Uma breve nota sobre diminutivos}

Como já colocado anteriormente, diminutivos não são tolerados no primeiro nome do composto ada, exatamente como ocorre com os compostos do tipo radical-palavra. Mas o que impediria que um diminutivo (ou aumentativo) ocorresse no primeiro nome de uma estrutura como (16)? Veja-se que se uma estrutura flexional está presente dentro da forma em ada, o que proibiria a diminutivização do primeiro nome do nosso composto?

Não tenho uma resposta para essa questão. Entretanto, vale observar que diminutivos idiomáticos são tolerados na forma em ada. Por exemplo, um estranho e improvável golpe com uma camisinha (preservativo) pode ser uma camisinhada. Nesse caso, o diminutivo muda completamente o significado do nome de base (camisa), o que parece estar relacionado com seu licenciamento na forma.

Se os diminutivos idiomáticos forem mais internos do que os não idiomáticos na estrutura morfossintática do nome, fica claro que o que quer que proíba a diminutivização do nome de base da forma em ada será alguma restrição imposta a uma camada mais externa deste nome - e que recai sobre um suposto diminutivo mais externo. Pode ser que diminutivos sejam compostos, envolvendo a camada \#, adjunções nessa camada (como defendem, para certos tipos de diminutivos, BACHRACH; WAGNER, 2007), e talvez haja uma restrição sobre a 
ocorrência de compostos desse tipo internamente ao composto ada, e a compostos do tipo radical-palavra de modo geral. Mas a natureza dessa restrição é ainda totalmente obscura para mim.

\section{CONSIDERAÇões FINAIS}

Neste trabalho, apresentei uma análise em que as nominalizações em -ada que denotam algo como golpe ou pancada com o instrumento $X$ (por exemplo, pedrada e pernada), em que $\mathrm{X}$ é definido pelo nome de base, são compostos do tipo $\mathrm{N}-\mathrm{N}$ em que temos o determinante precedendo o determinado. A proposta explica: 1. as terminações típicas de finais de palavras presentes em alguns nomes de base; 2. os plurais irregulares (e somente eles) em alguns nomes de base; 3. o fato de a terminação -(z)ada ter um significado enciclopédico não esperado em afixos (segundo os pressupostos da Morfologia Distribuída); 4. o fato de as formas em (z)ada terem dois acentos (làpiszáda).

Especificamente, a proposta em (16), em que a estrutura nominal mais encaixada é dominada por um nó \#, explica: 1. o fato de um referente para o nome de base ficar disponivel no discurso; 2 . o fato de o plural do nome de base também ficar disponivel para a retomada anafórica no discurso; 3 . os alomorfes plurais das raizes dos nomes de base da nominalização.

Por fim, o leitor poderia perguntar se zada e ada não deveriam ser itens diferentes, como defendem muitos autores para os supostos morfemas diminutivos -inho x -zinho (ver, por exemplo, LEE, 1992; entre outros).

Pela discussão precedente, fica claro que, na abordagem defendida aqui, zada e ada não são itens diferentes, e /z/ é uma consoante epentética. No que foi discutido anteriormente, a inserção da consoante é condicionada por características fonológicas da raiz (depois de determinados processos morfofonológicos ou fonológicos); portanto, não me parece haver uma boa razão para assumir que /z/ seja algo mais do que uma consoante epentética cuja inserção é condicionada pela rima da raiz do nome determinante. No caso dos diminutivos, uma mesma raiz pode receber uma ou outra forma (martelinho e martelozinho), e, portanto, a ocorrência de /z/ em -zinho é no máximo parcialmente (cafezinho versus *cafeinho ou *cafinho ou *cafinhe) determinada por propriedades fonológicas da raiz.

Algumas coisas ficaram sem uma explicação satisfatória, como a proibição de diminutivos no primeiro item, considerando que, segundo a proposta, um nó \# está presente. Uma investigação sobre os diminutivos e sua interação com outras classes e palavras e com compostos fica para investigação futura.

\section{ON MARTELADAS AND PEDRADAS AND THE STRUCTURE OF -ADA FORMS DERIVED FROM NOUNS}

Abstract: In this paper, following the framework of distributed morphology (HALLE; MARANTZ, 1993; MARANTZ, 1997), I investigate Brazilian Portuguese adanominals such as pedrada and cabeçada, and propose they should be analyzed as a sort of $\mathrm{N}-\mathrm{N}$ compound.

Keywords: Nominalizations. Compounds. Referentiality. Noun inflection. Distributed morphology. 


\section{REFERÊNCIAS}

ARAD, M. Locality constraints on the interpretations of roots: the case of Hebrew denominal verbs. Natural Lenguage and Linguistic Theory, v. 21, n. 4, p. 737778, 2003.

BACHRACH, A.; WAGNER, M. Syntactically driven cyclicity vs. output-output correspondence: the case of adjunction in diminutive morphology. U. Penn Working Papers in Linguistics, v. 10, n. 1, p. 1-16, 2007.

BECHARA, E. Moderna gramática portuguesa. Rio de Janeiro: Lucerna, 2003.

DI SCIULLO, A. M. Decomposing compounds. SKASE Journal of Theoretical Linguistics, v. 2, n. 3, p. 14-33, 2005.

EMBICK, D. Localism and globalism in morphology and phonology. Cambridge, MA: The MIT Press, 2010.

HALLE, M.; MARANTZ, A. Distributed morphology and the pieces of inflection. In: HALE, K.; KEYSER, S. J. (org.). The view from building 20. Cambridge: The MIT Press, 1993. p. 111-176.

IPPOLITO, M. On the past participle morphology in Italian. In: ARREGI, K. et al. (org.). Papers on morphology and syntax. Cycle One. MIT Working Papers in Linguistics, Cambridge, v. 33, p. 111-137, 1999.

KIPARSKY, P. Word formation and the lexicon. In: INGEMAN, F. (org.). Proceedings of the Mid-America linguistics conference. University of Kansas, 1982.

LEE, S.-H. Fonologia lexical do português. Cadernos de Estudos Linguísticos, Campinas, v. 23, p. 103-120, jul./dez. 1992.

LEE, S.-H. Sobre os compostos do PB. Delta, São Paulo, v. 13, n. 1, p. 17-33, 1997.

LEE, S.-H. Sobre a formação de diminutivo do português brasileiro. Revista de Estudos da Linguagem, v. 8, n. 1, p. 113-124, 1999. Disponivel em: http:// www.periodicos.letras.ufmg.br/index.php/relin/article/view/2303. Acesso em: 15 mar. 2020.

MARANTZ, A. No escape from syntax: don't try morphological analysis in the privacy of your own lexicon. In: DIMITRIADIS, A.; SIEGEL, L. et al. (org.). University of Pennsylvania Working Papers in Linguistics, Proceedings of the 21st Annual Penn Linguistics Colloquium, University of Pennsylvania, v. 4, n. 2, p. 201-225, 1997.

MARANTZ, A. Locality domains for contextual allomorphy across the interfaces. In: MATUSHANSKY, O.; MARANTZ, A. (org.) Distributed morphology today: morphemes for Morris Halle. Cambridge: The MIT Press, 2013. p. 95-116.

MEDEIROS, A. B. Traços morfossintáticos e subespecificação morfológica na gramática do português: um estudo das formas participiais. 2008. Tese (Doutorado) - Universidade Federal do Rio de Janeiro, Rio de Janeiro, 2008.

MEDEIROS, A. B. A molecada se empanturrou de bananada! Considerações sobre as nominalizações em -ada não-eventivas. ReVEL, v. 7, n. 12, p. 1-26, 2009. MINUSSI, R. D. Os nomes compostos no português brasileiro: uma análise morfossintática. ReVEL, edição especial n. 5, 2011.

NÓBREGA, V. A. Composição na Morfologia Distribuída: dos universais à variação. ReVEL, v. 13, n. 24, p. 87-119, 2015. 
DOSSIE

OLTRA-MASSUET, M. I. On the notion of theme vowel: a new approach to Catalan verbal morphology. 1999. Tese (Doutorado) - Massachusetts Institute of Technology, Cambridge, MA, 1999.

SCHER, A. P. Nominalizações em -ada em construções com o verbo leve dar em português brasileiro. Revista Letras de Hoje, Porto Alegre, v. 41, n. 1, p. 29-48, 2006. 